\title{
Reliability of quantitative and qualitative assessment of air leakage paths through reductive sealing
}

\author{
Vitor E.M. Cardoso ${ }^{\text {a, }}$, Nuno M.M. Ramos ${ }^{\text {a }}$, Ricardo M.S.F. Almeida ${ }^{\text {a,b }}$, Manuela Almeida $^{\text {, }}$, \\ Pedro F. Pereira ${ }^{a}$, Martin Prignon ${ }^{\mathrm{d}}$

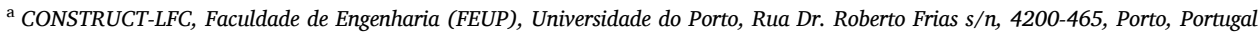 \\ ${ }^{\mathrm{b}}$ Polytechnic Institute of Viseu, School of Technology and Management, Department of Civil Engineering, Campus Politécnico de Repeses, 3504-510, Viseu, Portugal \\ ${ }^{\mathrm{c}}$ ISISE, Department of Civil Engineering (DEC), Escola de Engenharia da Universidade do Minho, Campus de Azurém, Guimarães, 4800-058, Portugal \\ ${ }^{\mathrm{d}}$ Université catholique de Louvain, Architecture et climat, 1 Place du Levant, 1348, Louvain-la-Neuve, Belgium
}

\section{A R T I C L E I N F O}

\section{Keywords:}

Airtightness

Air leakage

Blower door tests

Uncertainty analysis

Smoke tracer

ELA

\begin{abstract}
A B S T R A C T
A full characterization of a building air leakage is labour intensive. As results of laboratory and mock-up experimentation rarely portray in situ conditions, the assessment of real case studies bring added value. Still, the results of experimentation of the latter face more challenges than the former. In this work a full quantitative and qualitative assessment of air leakage paths is performed, using a light steel framing (LSF) modular building with structural insulated panels (SIPs) as case study. Blower-door measurements undergo for a sealing campaign of eleven steps, a technique often described as reductive sealing. Additionally, smoke tracer measurements were carried out to visually identify the air leakage locations. The application of three regression methods resulted in different uncertainty estimates. Less than $7 \%$ of the total air leakage was not attributed to one of the considered types of air leakage paths. Assessing less impacting leakage paths first and placing similar types of air leakage paths in a consecutive sealing order seems to be the most correct strategy when using the reductive sealing technique. On average, at a reference pressure difference of $4 \mathrm{~Pa}$, the sealing step uncertainty averaged, $9.9 \%$, $18.8 \%$, and $27.5 \%$, depending on the method used for regression of the blower door test results. Despite the highest calculated uncertainty, literature shows that the application of the method leading to it, Weighted Line of Organic Correlation (WLOC), provides the results in closer agreement with the observed uncertainty of measurements.
\end{abstract}

\section{Introduction}

\subsection{Air leakage paths assessment}

Although a vast number of factors affect airtightness, in practice, the air leakage paths are the physical interfaces that translate their impact on building performance $[1,2]$. Several researchers studied the impact and contribution of different building components to the overall airtightness.

The assessment of the air leakage distribution in detached houses in Finland $[3,4]$, by thermography, detected three typical air leakage paths roof-wall joints, floor-wall joints, and window-wall joints. A study in 32 lightweight detached houses in Estonia [5] found air leakage paths at envelope joints, including doors and windows, and envelope penetrations, such as ventilation ducts, electrical sockets and switches, and plumbing installation.

France and Belgium have extensive templates to assess air leakage location. The data gathered in those tests is stored in national whole building airtightness databases [6,7]. In the case of France, with more than 200 thousand dwellings analyzed, the most frequently identified leak locations include floor-wall joints, rolling shutter casing, ventilation air terminal devices, electrical grids on external walls, and sliding doors $[8,9]$.

While these researches focused on qualitative approaches, there are others aiming on quantitative ones. One of the methods available for the quantification of single components impact is the reductive sealing technique $[10,11]$. The reductive sealing consists on offsetting results from blower door tests, between consecutive sealing steps, and therefore attaining the performance of individualized elements. In studies performed in the UK [12-14], the leakage rates attributed to the background ranged from $45 \%$ to $75 \%$, after the assessment of permanent

\footnotetext{
* Corresponding author.

E-mail address: v.cardoso@fe.up.pt (V.E.M. Cardoso).
} 


\begin{tabular}{|c|c|c|c|}
\hline \multicolumn{2}{|c|}{ Abbreviations } & $\mathrm{q}_{\mathrm{m}}$ & Airflow rate corrected to standard temperature (air density \\
\hline OLSy & $\begin{array}{l}\text { Ordinary Least Square based on the distance to the } \\
\text { regression line }\end{array}$ & $\Delta \mathrm{p}$ & $\begin{array}{l}\text { (depressurization) temperatures }\left(\mathrm{m}^{3} / \mathrm{h}\right) \\
\text { Resulting pressure difference after all corrections }(\mathrm{Pa})\end{array}$ \\
\hline OLSuOrd & $\begin{array}{l}\text { inary Least Square based on the uncertainty on airflow } \\
\text { measurements }(-)\end{array}$ & $\Delta \mathrm{p}_{\mathrm{m}}$ & Measured pressure difference of $\mathrm{q}-\Delta \mathrm{p}$ pairs $(\mathrm{Pa})$ \\
\hline WLOCW & eight Line of Organic Correlation $(-)$ & $\Delta \mathrm{p}_{0 \mathrm{a}}$ & Zero-flow approximation component $(\mathrm{Pa})$ \\
\hline LSF & Light Steel Framing $(-)$ & $\mathrm{q}$ & Resulting airflow rate after all corrections $\left(\mathrm{m}^{3} / \mathrm{h}\right)$ \\
\hline LARWK & Liquid-Applied Polyurea Waterproofing Membrane $(-)$ & $\mathrm{T}$ & Interior(pressurization)/exterior(depressurization) \\
\hline SIP & Structural Insulated Panel (-) & & temperature $(\mathrm{K})$ \\
\hline EPS & Expanded Polystyrene $(-)$ & $\mathrm{C}_{\text {env }}$ & Airflow coefficient $\mathrm{m}^{3} /\left(\mathrm{h} \cdot \mathrm{Pa}^{\mathrm{n}}\right)$ \\
\hline OSB & Oriented Strand Board $(-)$ & $\mathrm{n}$ & Airflow exponent $(-)$ \\
\hline $\mathrm{u}()$ & Uncertainty $(-)$ & r() & Correlation coefficient $(-)$ \\
\hline $\mathrm{q}_{\text {env }}$ & $\begin{array}{l}\text { Airflow rate through the building envelope (interior/ } \\
\text { exterior air density correction) }\left(\mathrm{m}^{3} / \mathrm{h}\right)\end{array}$ & $\begin{array}{l}\text { ELA } \\
\text { ELA }_{d}\end{array}$ & $\begin{array}{l}\text { Effective leakage area }\left(\mathrm{cm}^{2}\right) \\
\text { Effective leakage area in depressurization }\left(\mathrm{cm}^{2}\right)\end{array}$ \\
\hline $\mathrm{T}_{\mathrm{e}}$ & Exterior temperature $(\mathrm{K})$ & ELA $_{\mathrm{p}}$ & Effective leakage area in pressurization $\left(\mathrm{cm}^{2}\right)$ \\
\hline $\mathrm{T}_{\mathrm{i}}$ & Interior temperature $(\mathrm{K})$ & $\rho_{0}$ & Air density at standard conditions $\left(20^{\circ} \mathrm{C}\right)\left(\mathrm{kg} / \mathrm{m}^{3}\right)$ \\
\hline $\mathrm{T}_{0}$ & Absolute temperature at standard conditions $\left(20^{\circ} \mathrm{C}\right)(\mathrm{K})$ & $\mathrm{C}_{\mathrm{D}}$ & Discharge coefficient $(-)$ \\
\hline $\mathrm{q}_{\mathrm{r}}$ & Airflow rate readings $\left(\mathrm{m}^{3} / \mathrm{h}\right)$ & ELA $_{\text {step }, \mathrm{i}}$ & Effective leakage area in sealing step $\left(\mathrm{cm}^{2}\right)$ \\
\hline
\end{tabular}

vents, windows, doors, their joints with the envelope, attic hatches, and several other joints. Still, some of these values may occur due to the additional challenges of air tightening commissioned buildings [15]. The importance of their quantification is relevant when high leakage levels are still present after the air leakage paths identified as the most contributable are measured [16].

Generally, the identification of leakage paths is qualitative and not quantitative. When it is quantitative, it is mostly not extensive. As the identified air leaks only represent a portion of the total air leakage area, since the remaining ones reveal themselves challenging to spot, one wonders if there are limits on the extension of identified leaks by this technique. Additionally, one questions if the combination of qualitative techniques can provide an optimized sealing sequence for quantification of air leakage paths contributions.

\subsection{Results reliability}

When quantifying airtightness by fan pressurization tests there are three common types of errors: precision and bias errors on measurements and modelization errors on the used model [17,18].Wind speed and direction fluctuations are one of the main sources of precision and modelization errors [19]. The zero-flow measurements intend to tackle part of it, but still, for uncertainty purposes, the assumptions made show significant importance $[20,21]$. In addition to these errors there is the influence of the tester behaviour, which is the main reason behind certification programmes for testers and quality management schemes [22, 23].

During an in-situ measurement campaign of the contribution of different elements to the overall airtightness performance, one of the characteristics that is outputted and is widely used in building simulation is the ELA. For its usefulness on scenarios design and comparison, lists of ELAs by components were developed and compiled in libraries for quick access. Interesting examples can be found in AIVC [24] and ASHRAE [25] documentation.

The reliability of fan pressurization measurements has been the object of study for a while now [26,27]. The uncertainty in fan pressurization measurements is non-negligible in both the two measured variables: airflow volume and pressure differential [28,29]. In addition the uncertainties are not constant in the pressure stations during a test [30].

More recently, these issues are getting tackled by the adoption of alternative regression methods, that include the weighting of the uncertainty for each pressure-airflow measurement in a test, and by the consideration of a larger amount of error sources in the calculation of the total uncertainty [31-33]. The weighting allows for the addressing of the non-constant uncertainties in both the measured variables.

The progress made brings a significant potential contribution to the reliability of fan pressurization measurements and confidence in the subsequent data treatment. This is relevant since one of the main limitation found in the literature is that the uncertainty estimation and propagation during data treatment is scarce and only one regression method is applied [34,35]. One questions if the sealing sequence affect the uncertainty of results and how is uncertainty dependent on the applied regression method during the data treatment phase.

\subsection{Gaps and objectives}

The literature shows that there is already relevant knowledge on typical air leakage paths. The reliability of the evaluation of air leakage paths through in-situ tests, however, requires further developments.

The present work intends to fill the gap by focusing on the evaluation of the reliability of quantitative and qualitative assessment of air leakage paths with the reductive sealing technique.

The main objectives of the present work are as follow:

- Make an in-depth discussion of the evaluation of air leakage paths, using a modular building as a case study;

- Check the strengths and weaknesses of using a smoke tracer as a qualitative technique for the detection of leaks;

- Evaluate the uncertainties resulting from the application of standard and recently evaluated regression methods on variables of interest, such as airflow rates and effective leakage areas, and produce recommendations for the reliable application of the reductive sealing technique.

\section{Methodology and case study}

\subsection{Work plan and case study}

The work plan was developed according to the following steps:

- Selection of case study;

- Definition of a reductive sealing plan;

- Implementation of the in-situ testing campaign;

- Uncertainty analysis of the test results. 
The selected case study is a small modular construction building, assembled with a non-volumetric preassembly structural insulated panels (SIPs) with light steel framing (LSF) (Fig. 1), located in Porto, Portugal. Studies on the airtightness performance of this constructive solution (SIPs) is available in the literature [36]. This type of building was selected because its construction procedure, meant to be highly standardised, should include a systematic detection and treatment of unintended leaks.

The building is one floor only, with $33.6 \mathrm{~m}^{2}$ of floor area and a volume of $85.7 \mathrm{~m}^{3}$, and the envelope solutions are common in this type of buildings. Fig. 2 shows the design details of exterior building components. In the exterior walls, SIPs have insulation boards of EPS 30 with a thickness of $153 \mathrm{~mm}$. The connection of the SIPs is done through U steel profiles filled with EPS 30 thermal insulation. The joints were sealed with extruded mastics on both faces. The roof constructive solution has a similar configuration to the wall solution, with an additional continuous liquid-applied polyurea waterproofing membrane (LARWK) on the exterior side and on the interior side a non-ventilated cavity, mineral wool boards and gypsum boards fixed to the LSF beams. The slab constructive solution does not use SIPs. It encompasses the same type of LSF beams supporting a solution of OSB3 panel of $12 \mathrm{~mm}, 40 \mathrm{~mm}$ of mineral wool boards of $70 \mathrm{~kg} \mathrm{~m}^{-3}$ with embedded OMEGA profiles to support, and an additional OSB3 panel of $25 \mathrm{~mm}$, before the application of the floor finishing material. Regarding ventilation and airtightness, the building has a balanced system and all the windows and doors have an air permeability of class 4 [37].

The campaign followed an 11-step reductive sealing. The temporary sealing was made with paint stripes and plastic coverings when seen appropriate.

The stages were the following in a cumulative and progressive order of sealing: default mode (DEF); mechanical ventilation (MEV); heating and air conditioning elements (HAC); electrical appliances (ELE); lighting (LIG); plumbing (PLU); wall/wall joints (WWJ); wall/floor joints (WFJ); wall/roof joints (WRJ); wall/openings joints (WOJ); openings (OPE); and entrance door (ENT). In each of the steps, the referred elements were sealed, one pressurization and one depressurization test were made, followed by a smoke tracer pressurization test for further air leakage detection.

After the first test, default test (DEF), the smoke tracer test identified the main leakage paths. The aim was to reduce the air leakage of the case study as much as possible, but also to consecutively address similar types of air leakage paths: $1 \mathrm{D}$-item/point leakage; 2D - linear leakage. As the leaks were being progressively identified they were addressed, together with the similar types, i.e., identification of ELE and addressing consecutively LIG and PLU. While the openings, OPE, were identified as one of the largest contributors, they were to be assessed consecutively to the entrance door, ENT, and this one needed to be last for access reasons. All the tests for the determination of airtightness followed the ISO 9972:2015 [38] standard guidelines. Zero-flow pressure readings were taken before and at the end of the pressure stations measurement, each time with a collection of 10 points with $30 \mathrm{~s}$ duration each. Pressure-flow couples were measured at 10 points, from 65 to $15 \mathrm{~Pa}$, equally spaced, with $30 \mathrm{~s}$ duration each.

The lower limit was chosen to comply with the guidelines of the standard and equipment characteristics. Regarding the upper range, while the standard indicates it could go as high as $100 \mathrm{~Pa}$ in a measurement, it only requires that the highest-pressure difference shall be recorded at least at $50 \mathrm{~Pa}$. As it was intended to apply common procedures usually adopted by practitioners, the value of 65 Pa was used.

Smoke tracer tests followed ISO 9972:2015 and ASTM E1186:2017 [39] guidelines. The building was pressurized at $100 \mathrm{~Pa}$ for $15 \mathrm{~min}$ with simultaneous smoke generation to allow for the homogenization of the smoke indoors and the taking of photographic evidence.

\subsection{Equipment}

The campaign comprehended two types of measurements: fan pressurization and smoke tracer leakage location. Fig. 3 portrays the equipment used for quantitative and qualitative airtightness assessment. For the proposed work, a Retrotec 1000 model, together with a DM-2 gauge, was used in the collection of pressure-flow couples and zeroflow pressure measurements. The gauge has a pressure resolution of $0.10 \mathrm{~Pa}$ and an accuracy of $\pm 1 \%$ of the pressure reading or $0.15 \mathrm{~Pa}$, whichever is greater [40]. With the used setups, the fan model has an accuracy of $\pm 3 \%$ of the airflow measured [41], limited to readings above $10 \mathrm{~Pa}$. In a fan pressurization test, an adaptive structure is placed at an opening, door, or window commonly, with an attached fan connected to a manometer. The calculation of airflows for several theoretically uniform static pressure differentials allows the extrapolation outside of the measurement range to assess the leakage under natural conditions.

A Cameo Steam Wizard 2000 with slow fog served for the visual detection of air leakages. Not only the airtightness of envelopes or components is critical in the infiltration assessment of buildings, but also knowing the locations of air leakages is essential. Air leakage location methods used in conjunction with pressurization tests improve their identification. Smoke tracer is a useful qualitative indicator of air leaking locations [45].

During the campaign, an indoor temperature sensor and a nearby weather station were used to provide continuous monitoring of interior $\left(\mathrm{T}_{\mathrm{i}}\right)$ and exterior $\left(\mathrm{T}_{\mathrm{e}}\right)$ temperatures, as well as wind speeds $(\mathrm{v})$. The accuracy on the indoor sensor is $\pm 0.5{ }^{\circ} \mathrm{C}$ and its resolution is $0.1{ }^{\circ} \mathrm{C}$. Temperature sensors on the weather station have an accuracy of $\pm 0.3^{\circ} \mathrm{C}$ and a resolution of $0.1^{\circ} \mathrm{C}$. The $\mathrm{v}_{\min }, \mathrm{v}_{\text {mean }}$ and $\mathrm{v}_{\max }$ represent the minimums, means and maximums, respectively, of the wind speed during the test periods. Table 1 synthesises the measured variables.

\subsection{Uncertainty analysis}

The air flow coefficient before correction to standard conditions,

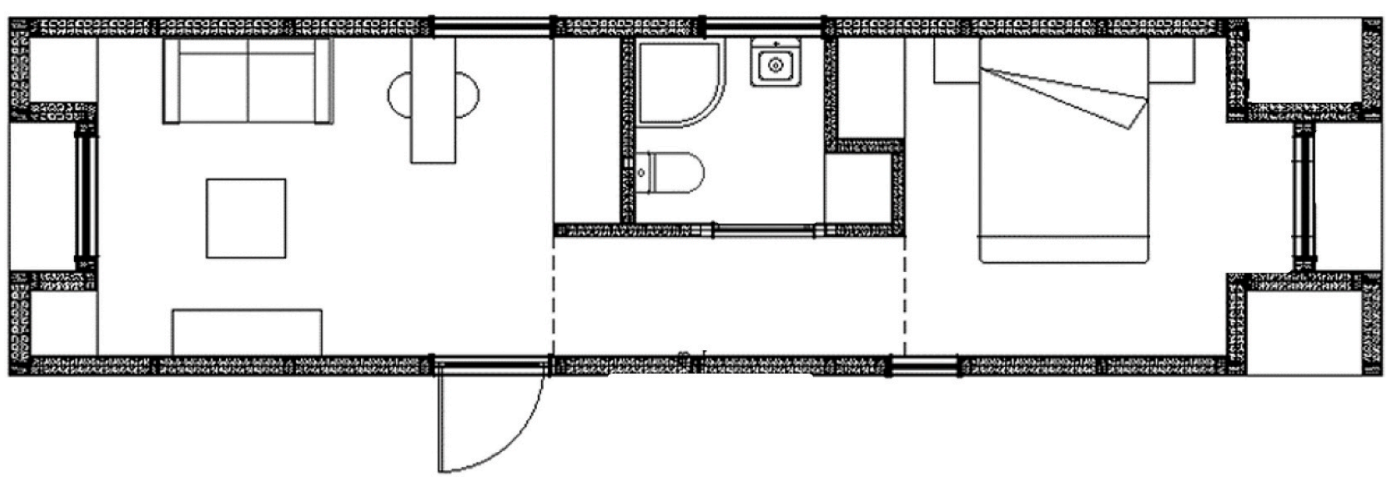

Fig. 1. Case study modular building floor plan. 
a)

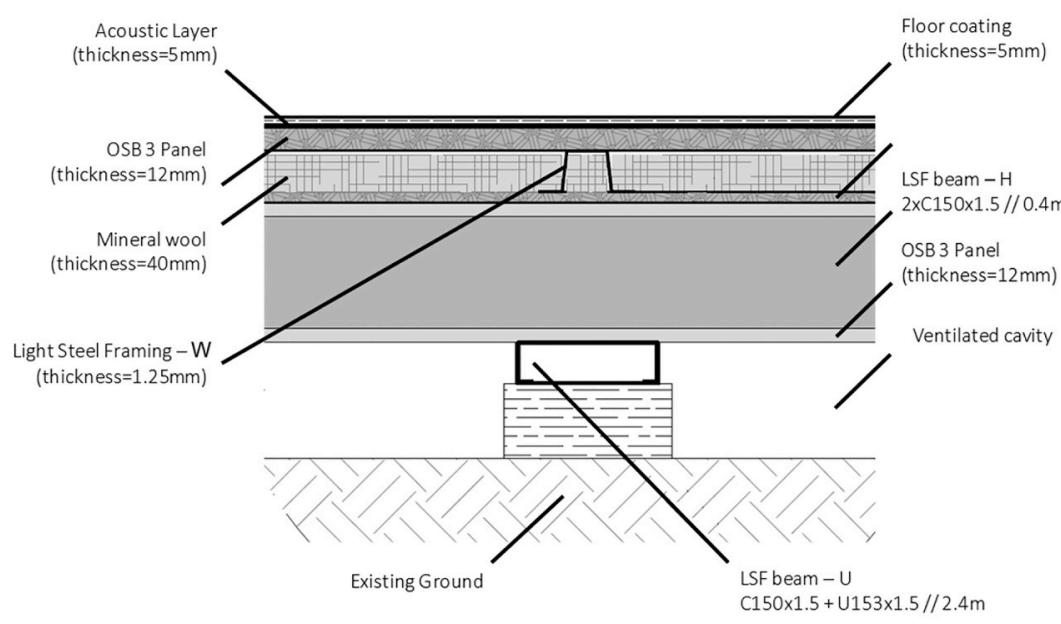

Exterior b) Interior

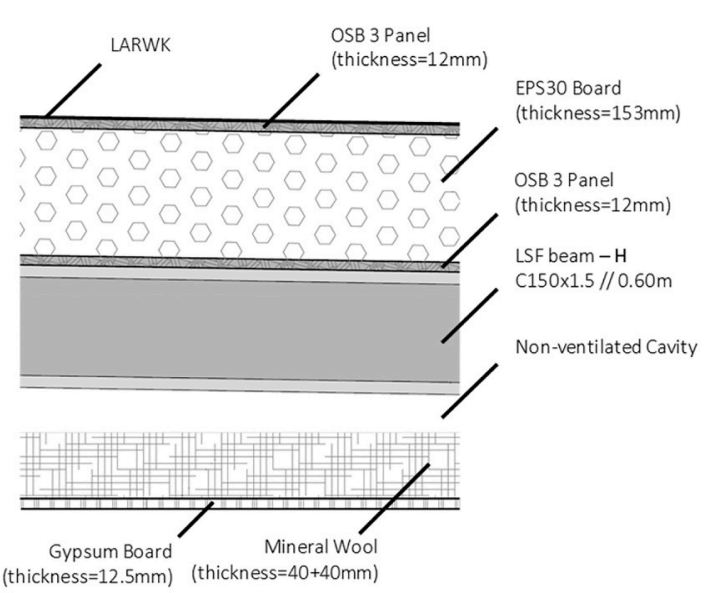

Exterior

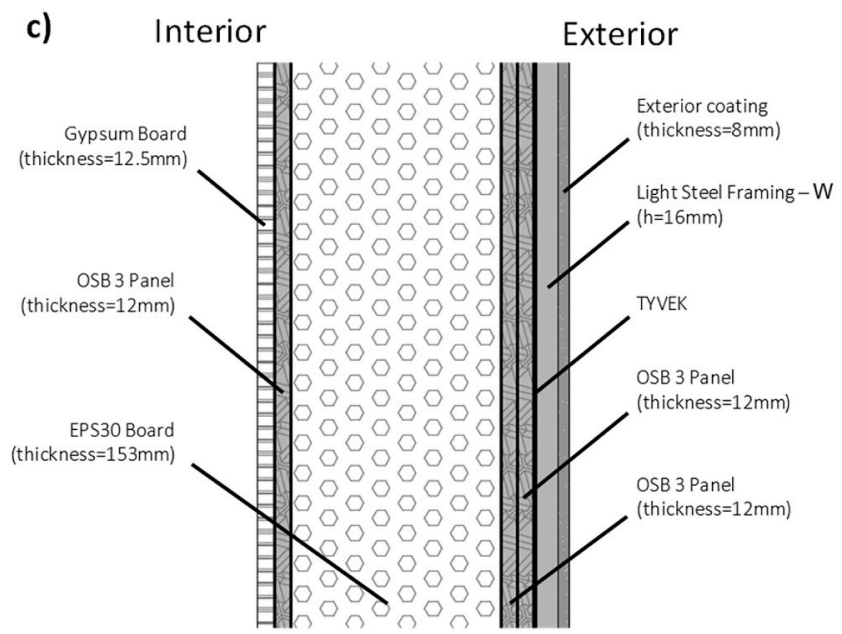

d)

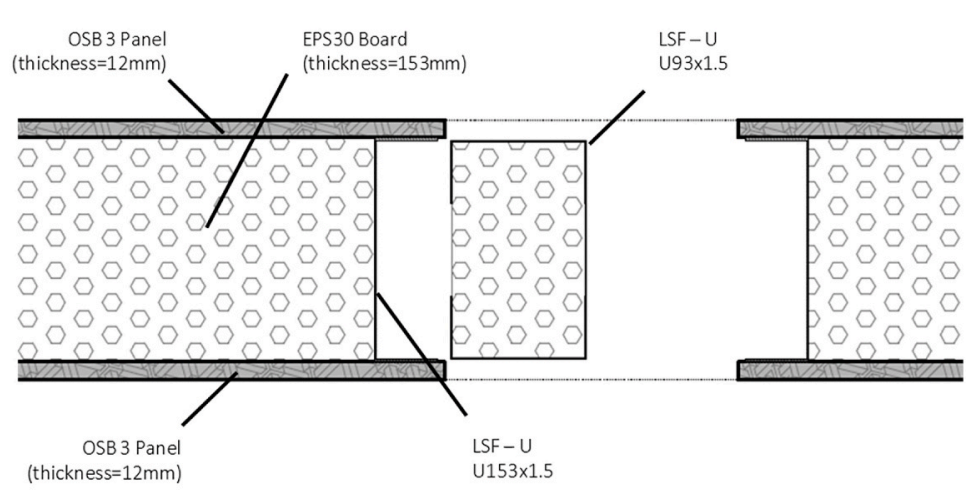

Fig. 2. Design details of exterior building components: a) floor, b) roof, c) exterior wall, and d) exterior SIP connection.

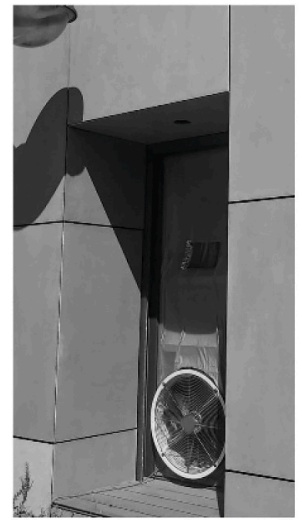

a)

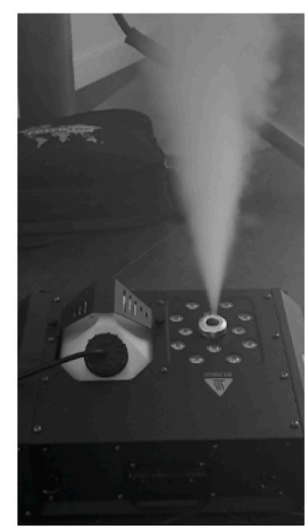

b)

Fig. 3. Equipment used on the campaign: a) blower-door apparatus; b) smoke generator.

$\mathrm{C}_{\mathrm{env}}$, represents, amongst the effect of the air densities of indoor and outdoor, the joint product of the discharge coefficient and the leakage area (Eq. (1)). ISO 9972 assumes it equal to 1.0 (Eq. (2)), more in line with leaks of reduced dimensions [42], and the assumption of the

Table 1

Registered weather conditions during the campaign measurements.

\begin{tabular}{llllll}
\hline & $\mathrm{Te}\left[{ }^{\circ} \mathrm{C}\right]$ & $\mathrm{Ti}\left[{ }^{\circ} \mathrm{C}\right]$ & $\mathrm{v}_{\min }[\mathrm{m} / \mathrm{s}]$ & $\mathrm{v}_{\operatorname{mean}}[\mathrm{m} / \mathrm{s}]$ & $\mathrm{v}_{\max }[\mathrm{m} / \mathrm{s}]$ \\
\hline Minimum & 20.4 & 23.6 & 0.1 & 0.6 & 0.7 \\
Average & 24.9 & 27.2 & 1.0 & 1.4 & 1.8 \\
Maximum & 31.2 & 31.9 & 2.0 & 2.5 & 3.1 \\
Std. Deviation & 3.24 & 2.48 & 0.44 & 0.51 & 0.68
\end{tabular}

development of full turbulent flow in the air leakage paths. It implies that the air flow resistance is dominated by the edges of the air leaks and not by viscous ones, characteristic of laminar flows [43]. As one intends on applying the ISO standard, this assumption is adopted in the present work. In Eq. (1) and Eq. (2), the T stands for the exterior temperature in depressurization mode or interior temperature in pressurization mode.

$q=C_{e n v}\left(\frac{T_{0}}{T}\right)^{1-n} \Delta p^{n}$

$E L A=\frac{10 q}{3.6} \frac{\sqrt{\frac{\rho_{0}}{2 \Delta p}}}{C_{D}}=\frac{10}{3.6} C_{e n v}\left(\frac{T_{0}}{T}\right)^{1-n}\left(\frac{\rho_{0}}{2}\right)^{0.5} \Delta p^{n-0.5}$

In order to evaluate the reliability of results, the standard regression 
method of the EN9972:2015, OLSy, and its respective approach to uncertainty calculation, was compared to two alternatives:

- OLSu, same regression method of OLSy, but the approach on calculation uncertainty is based on the uncertainty in the measured airflow rates and temperatures, instead of the distances between the measured airflow rates and the regression line; depressurization test. The $\mathrm{q}_{\mathrm{r}}$ is the airflow rate reading, $\mathrm{q}_{\mathrm{m}}$ and $\mathrm{q}_{\mathrm{env}}$ are the measured airflow rate and the airflow rate through the building envelope, respectively, and result from corrections dependent on the interior and exterior temperatures. As for the pressure differential, both the accuracy and resolution of the gauge were used as well as the zero-flow approximation component (Eq. (4)) [18].

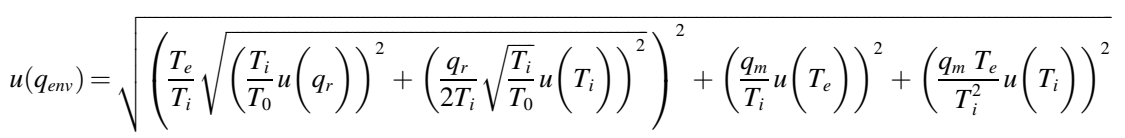

- WLOC, different regression method from OLSy, uncertainty includes weights based on the uncertainty of reading of airflow rates, temperatures, and pressure differentials, as well as a component for the zero-flow approximation.

The inclusion of OLSu serves as a benchmark for the total influence of the fan accuracy on the measurement uncertainty. Since the results from the use of IWLS and WLOC have shown to be very similar [28], only the latter was considered for comparison with the OLS regression method. Fig. 4 presents a flow chart of the variables and calculation procedure for the uncertainty assessment.

The full WLOC regression method structure and development can be found in the literature $[21,30,33]$. For the uncertainties in the airflow rate, both the resolution and accuracy of the fan and the temperature sensors uncertainty were taken into account. Eq. (3) represents the combined uncertainty of the different sources of errors considered for a
$u(\Delta p)=\sqrt{u^{2}\left(\Delta p_{m}\right)+u^{2}\left(\Delta p_{0 m}\right)+u^{2}\left(\Delta p_{0 a}\right)}$

The accuracy and resolution uncertainties of the used equipment were considered as uniform distributions while the standard deviation on zero-flow pressure was approximated as a normal distribution, as pointed in recently developed work [20,31]. These sources of error and their joint uncertainty are used in the quantification of weights for the application of WLOC.

Following the linearization of the measurements and the application of the two methods, error propagation of the regression parameters was applied for the estimation of the total uncertainty of the variables of interest. In Eqs. (5) and (6), T stands for the exterior temperature in depressurization mode or interior temperature in pressurization mode. As the regression parameters are correlated, a term including their respective covariance is added.

$u(q)=\sqrt{\begin{array}{c}\left(C_{e n v} \Delta p^{n}\left(\frac{T_{0}}{T}\right)^{1-n} \ln \left(\Delta p \frac{T}{T_{0}}\right) u(n)\right)^{2}+\left(C_{e n v} \Delta p^{n}\left(\frac{T_{0}}{T}\right)^{1-n} u\left(\ln \left(C_{e n v}\right)\right)\right)^{2}+\left(\frac{C_{e n v}(n-1)}{T} \Delta p^{n}\left(\frac{T_{0}}{T}\right)^{1-n} u(T)\right)^{2}+ \\ 2\left(C_{e n v} \Delta p^{n}\left(\frac{T_{0}}{T}\right)^{1-n}\right)^{2} \ln \left(\Delta p \frac{T}{T_{0}}\right) u(n) u\left(\ln \left(C_{e n v}\right)\right) r\left(n, \ln \left(C_{e n v}\right)\right)\end{array}}$

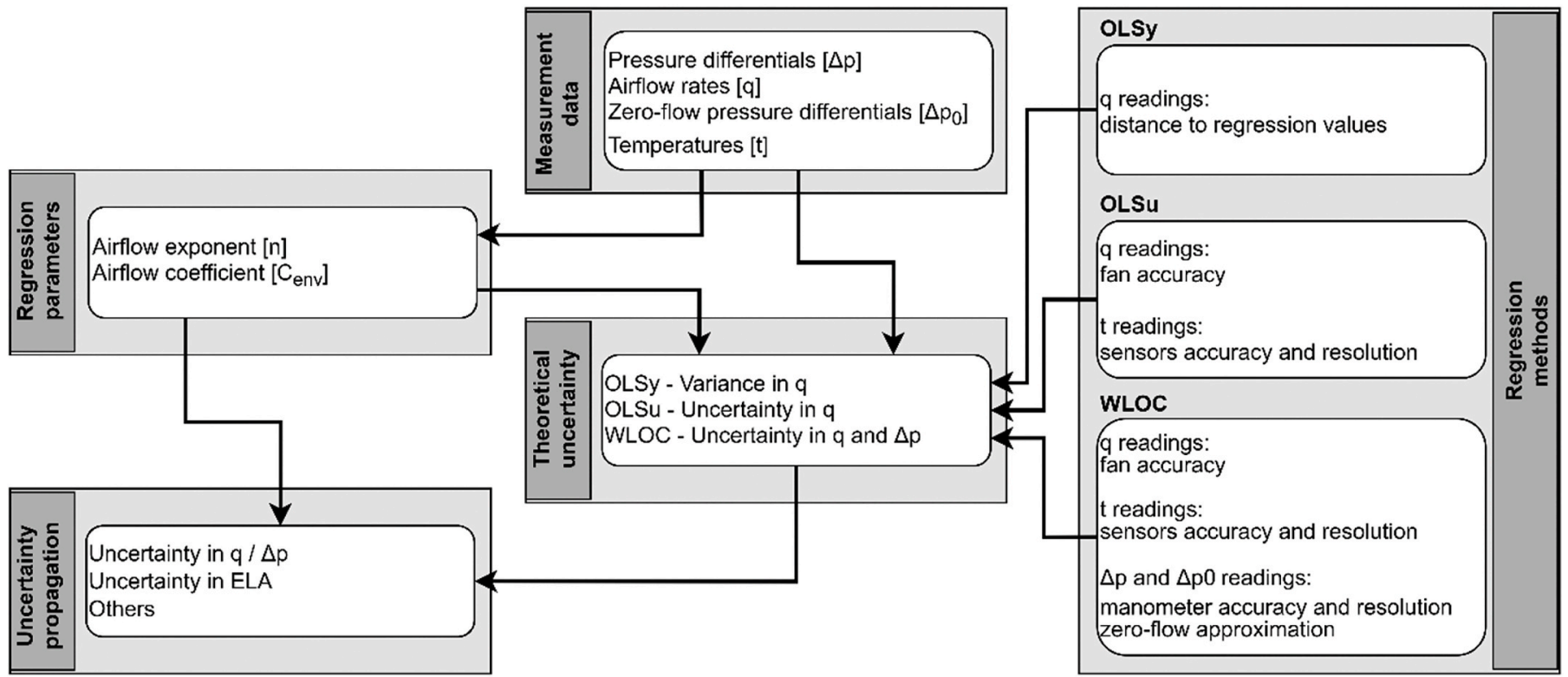

Fig. 4. Uncertainty analysis procedure. 


$$
\begin{aligned}
& \left(2.155 C_{e n v} \Delta p^{n-0.5}\left(\frac{T_{0}}{T}\right)^{1-n} \ln \left(\Delta p \frac{T}{T_{0}}\right) u(n)\right)^{2}+\left(2.155 C_{e n v} \Delta p^{n-0.5}\left(\frac{T_{0}}{T}\right)^{1-n} u\left(\ln \left(C_{e n v}\right)\right)\right)^{2}+ \\
& u(E L A)=\quad\left(2.155 \frac{C_{e n v} \Delta p^{n-0.5}(n-1)}{T}\left(\frac{T_{0}}{T}\right)^{1-n} u(T)\right)^{2}+ \\
& 2\left(2.155 C_{e n v} \Delta p^{n-0.5}\left(\frac{T_{0}}{T}\right)^{1-n}\right)^{2} \ln \left(\Delta p \frac{T}{T_{0}}\right) u(n) u\left(\ln \left(C_{e n v}\right)\right) r\left(n, \ln \left(C_{e n v}\right)\right)
\end{aligned}
$$

As the previous equation provides results on the uncertainty of the airflow rate and ELA for pressurization or depressurization modes separately, in order to provide a single result characterizing the leakage path, one needs to average the two results (Eq. (7)).

$u(E L A)=\sqrt{\frac{u\left(E L A_{d}\right)^{2}+u\left(E L A_{p}\right)^{2}}{4}}$

In a process of reductive sealing, the value at each step must be subtracted from the preceding sealing step (Eq. (8)). As the results of airflow rates from one step to the other are dependent on the preceding results, the uncertainties must be combined to compute the uncertainty of the airflow rate offset for each step (Eq. (9)).

$E L A_{\text {step }, i}=E L A_{i-1}-E L A_{i}$

$u\left(E L A_{\text {step }, i}\right)=\sqrt{u\left(E L A_{i-1}\right)^{2}+u\left(E L A_{i}\right)^{2}}$

\section{Results}

\subsection{Quantitative analysis - airflow rates}

Table 2 shows the airflow rate results in each step of the reductive sealing for a pressure difference of $50 \mathrm{~Pa}\left(\mathrm{q}_{50}\right)$. All the values correspond to the average of pressurization and depressurization tests. The results are obtained by the application of both regression methods and the corresponding difference between them is presented in percentage. In relation to the average values airflow the results have negligible differences between OLS and WLOC, never exceeding $0.64 \mathrm{~m}^{3} \mathrm{~h}^{-1}$ and averaging $0.17 \mathrm{~m}^{3} \mathrm{~h}^{-1}$. This is in line with previous applications of this methodology $[28,33]$.

\subsection{Qualitative analysis - smoke tracer}

The smoke tracer permitted to pinpoint the precise location of some air leaks. The most relevant ones were: MEV and HAC - through ceiling penetrations; ELE and LIG - through the technical electrical board and the connection with the shutters; OPE and ENT - through the joints. Fig. 5 portrays the main air leakage paths found with the smoke tracer.

Although the smoke tracer technique provides important visual data, some difficulties were encountered throughout the procedure. The main one occurs when there is a cladding system on the facades that includes an air gap. In this case, the smoke can move through the air layer between the structured insulated panels and the cladding itself, hiding the precise location of the air leakage paths or even leading to false conclusions. An example is the smoke that appeared in the perimeter of the roof area. Despite an apparent substantial reduction in the WWJ and WFJ sealing steps, the identification of the origin at the walls or floor interfaces of the envelope was not feasible.

The authors recommend that the use of other methods, such as thermography if the temperature gradient is adequate [44], could provide a good complement for the qualitative assessment. Still, because of the low temperature difference between indoor and outdoor during the period of the measurement campaign, this method was not applied, as it would not produce suitable results.

\subsection{Regression parameters $-n$ and $C_{e n v}$}

On average, the values of the regression parameters experience low difference between the OLS and WLOC regression methods, $0.42 \%$ for $\mathrm{n}$, and $0.98 \%$ for $\mathrm{C}_{\text {env. }}$. Fig. 6 and Fig. 7 represent the calculated values and uncertainties on $n$ and $C_{e n v}$, respectively, obtained by the use of the OLSy, OLSu and WLOC regression methods. The ranges provided result from the application of a positive and negative boundary $(\mathrm{y}-\mathrm{u}(\mathrm{y}) ; \mathrm{y}+\mathrm{u}$ (y)) around the calculated values.

The average uncertainty of $\mathrm{n}$ was $0.009,0.012$ and 0.019 for OLSy, OLSu, and WLOC, respectively. For $\mathrm{C}_{\text {env }}$, the uncertainty, in the same order, averages $0.58,0.95$, and $1.41 \mathrm{~m}^{3} \mathrm{~h}^{-1} \mathrm{~Pa}^{-\mathrm{n}}$. The phenomenon was expected since $\mathrm{OLSu}$, includes additional sources of error in comparison with OLSy, in particular relative to airflow and temperature readings.

The WLOC method adds on top of OLSu the contribution of pressure differential readings, including the direct effect of wind with the zeroflow approximation component. A simple linear model $\varepsilon=(0.11+$ $0.98 \sigma$ ) was found to be a proper predictor of this component [31], being $\sigma$ the standard deviation of the measured zero-flow pressure points. As the points distribution tested significant for normality [20], considering an interval containing $50 \%$ of its values results in $\varepsilon / 1.35$.

The difference between WLOC and OLSu is thus highly influenced by the wind. Fig. 8 confirms the almost linear correlation between the difference in uncertainty when using WLOC and OLSu at $4 \mathrm{~Pa}$ of pressure difference and the zero-flow approximation component.

The normal distribution of the zero-flow pressure points is confirmed by the results of the Kolmogorov-Smirnov ( $D=0.17, p=0.08$ ) and Shapiro-Wilk tests ( $\mathrm{D}=0.91, \mathrm{p}=0.25)$, in line with previous findings in the literature [20]. Ratios between the considered regression methods were calculated and presented in Table 3. They represent the number of times the uncertainty of a certain regression method, in this case OLSu and WLOC, fits in the uncertainty calculated by a defined base regression method, OLSy. The average values are in fair accordance with mean

\begin{tabular}{|c|c|c|c|c|c|c|c|c|c|c|c|c|}
\hline & DEF & MEV & HAC & ELE & LIG & PLU & WWJ & WFJ & WRJ & WOJ & OPE & ENT \\
\hline OLS $\left[\mathrm{m}^{3} \mathrm{~h}^{-1}\right]$ & 802.36 & 689.66 & 552.27 & 487.98 & 440.61 & 437.40 & 401.87 & 353.95 & 291.33 & 269.98 & 145.01 & 51.32 \\
\hline WLOC $\left[\mathrm{m}^{3} \mathrm{~h}^{-1}\right]$ & 802.16 & 689.43 & 552.16 & 487.97 & 440.11 & 436.76 & 401.48 & 353.86 & 291.41 & 270.03 & 145.03 & 51.32 \\
\hline Difference [\%] & 0.02 & 0.03 & 0.02 & 0.00 & 0.11 & 0.15 & 0.10 & 0.02 & 0.03 & 0.02 & 0.01 & 0.01 \\
\hline
\end{tabular}

Table 2

Average $\mathrm{q}_{50}$ results and their difference for the sealing steps using OLS and WLOC. 

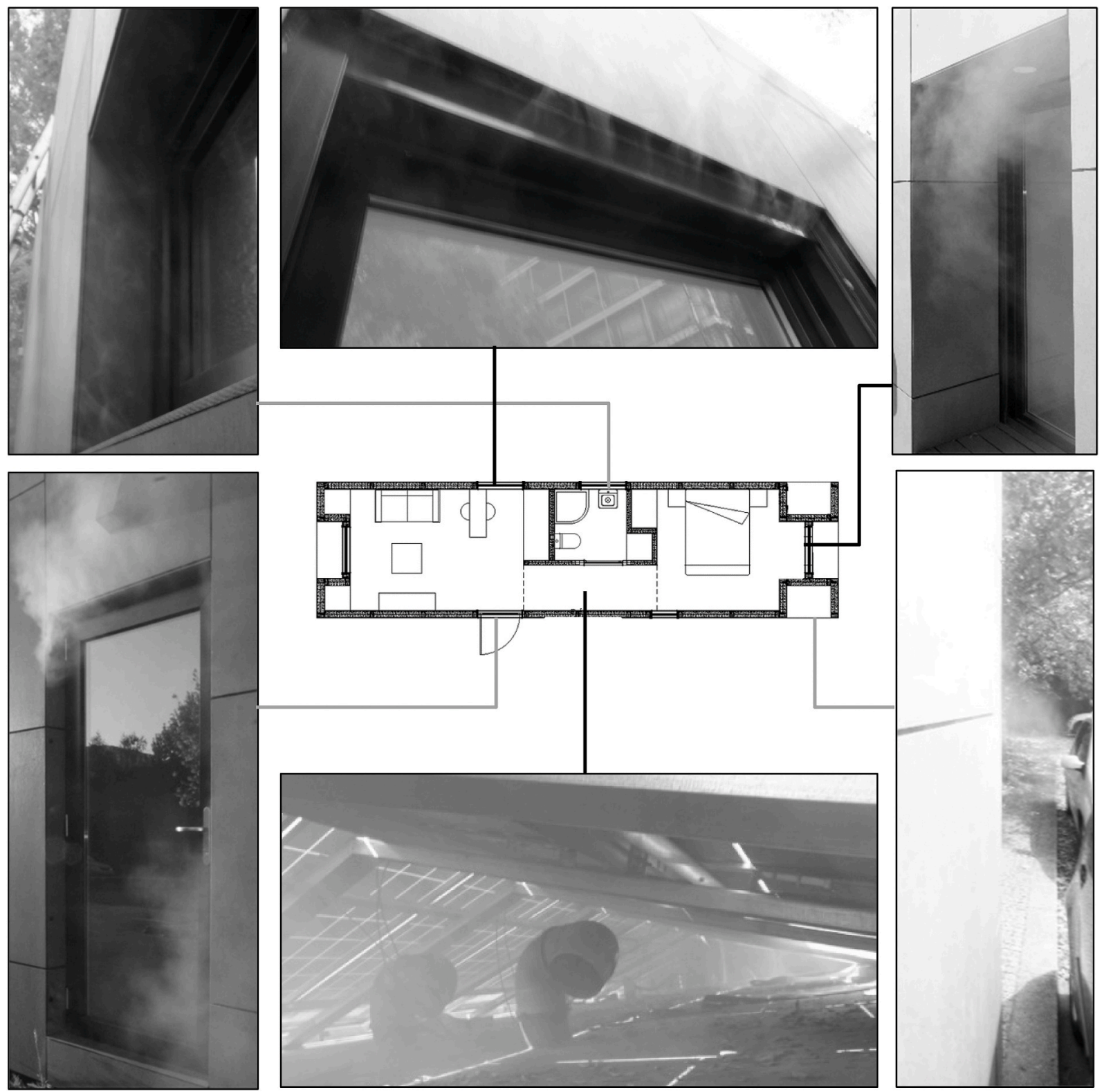

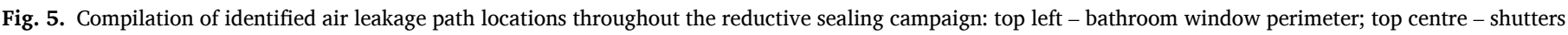

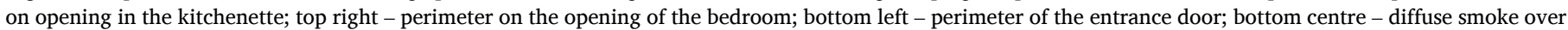
the roof; bottom right - perimeter of door giving access to the electrical board.

results from the most comprehensive study to date on the subject [33].

\subsection{Variables of interest $-q$ and ELA}

If one intends to establish an accurate level of uncertainty of variables dependent on the parameters exposed in the last subchapter, such as airflow rates and effective leakage areas, an analysis of the error propagation must be carried out. As previously discussed, the partial (OLSu) or complete (WLOC) components concerning accuracy and resolution of the used equipment, pressure gauge, fan and thermometers, together with the input of zero-flow approximation, were used to compute the theoretical uncertainties. Fig. 9 reports the distribution of uncertainties on airflow rates of each sealing step (average of pressurization and depressurization) at several pressure differences with the assumed methods on uncertainty quantification. Note that the use of the average significantly reduces overall uncertainty on variables of interest (see Eq. (7)).
Meaningful variations can be observed between methods. As expected, WLOC provides higher calculated uncertainties than the other two methods, on average, 2.6 and 1.7 times greater than OLSy and OLSu, respectively.

The rather compact distribution of values in OLSu is the result of the consideration of the accuracy and resolution range of the fan and temperature sensors readings as the only ones impacting the uncertainty of results. In other words, the OLSu is the method with the highest independence from pressure readings uncertainty. The other two methods are considerably influenced by the pressure components. In OLSy the value is dependent on a regression line that uses pressure readings as input. In WLOC the uncertainty is influenced by the accuracy and resolution of the manometer and the zero-flow approximation component. These aspects contribute to the higher dispersion of values in the results obtained with these methods.

Regarding ELAs and focusing on average values of the 12 pairs of pressurization and depressurization tests, the uncertainty for changing 


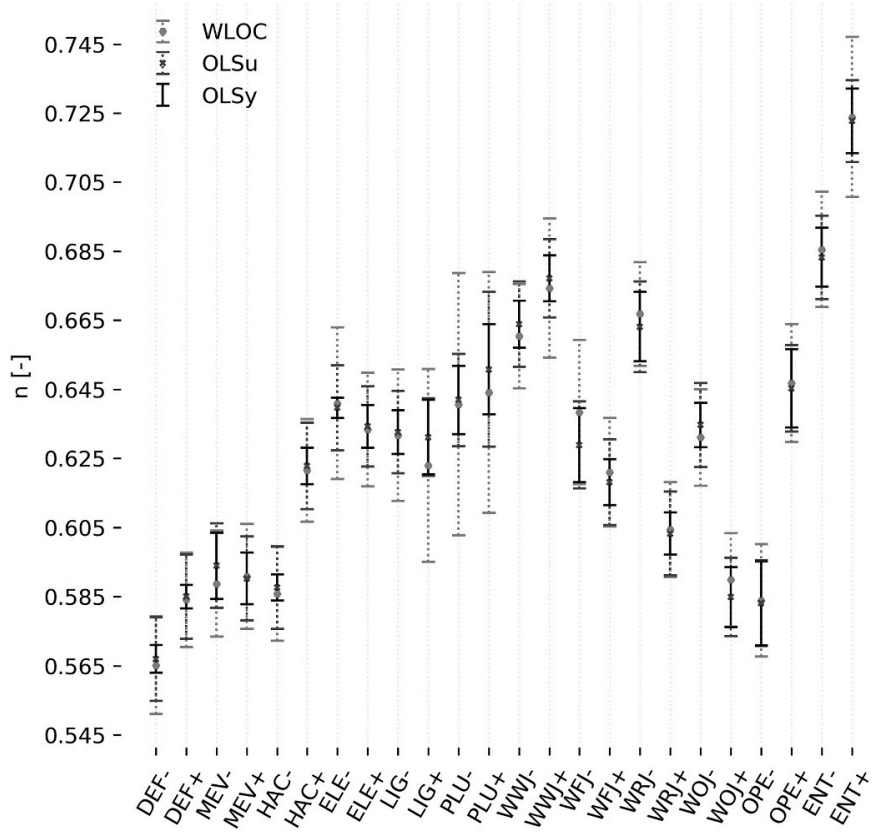

Fig. 6. Calculated uncertainty of $n$ values in each campaign measurement using OLSy, OLSu, and WLOC (+pressurization/- depressurization).
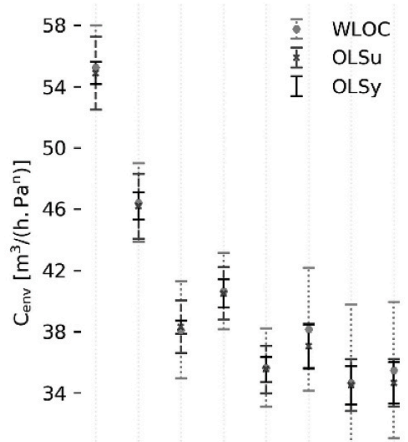

$30-$

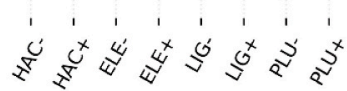

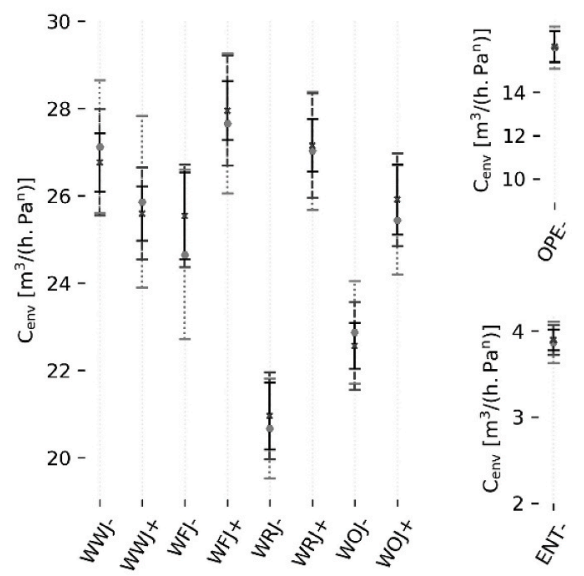

Fig. 7. Calculated uncertainty of Cenv values in each campaign measurement using OLSy, OLSu, and WLOC (+pressurization/- depressurization).

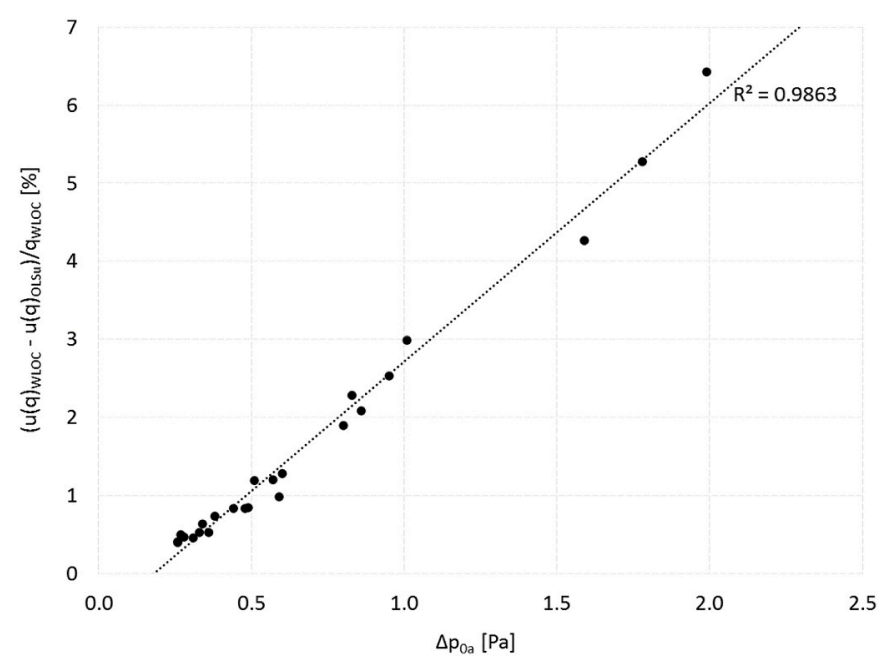

Fig. 8. Correlation between the difference in uncertainty when using WLOC and OLSu at $4 \mathrm{~Pa}$ of pressure difference and the zero-flow approximation component.

Table 3

Average uncertainty ratios of OLSu and WLOC to OLSy for both regression parameters.

\begin{tabular}{|c|c|c|c|c|c|}
\hline \multirow{2}{*}{$\begin{array}{l}\text { Regression } \\
\text { parameter }\end{array}$} & \multirow{2}{*}{$\begin{array}{l}\text { Airflow } \\
\text { direction }\end{array}$} & \multicolumn{4}{|l|}{ Average ratio } \\
\hline & & $\begin{array}{l}\text { Literature u } \\
(\mathrm{OLSu}) / \mathrm{u} \\
\text { (OLSy) [33] }\end{array}$ & $\begin{array}{l}\mathrm{u} \\
\text { (OLSu)/ } \\
\mathrm{u} \text { (OLSy) }\end{array}$ & $\begin{array}{l}\text { Literature u } \\
(\text { WLOC) } / \mathrm{u} \\
\text { (OLSy) [33] }\end{array}$ & $\begin{array}{l}\mathrm{u} \\
\text { (WLOC)/ } \\
\mathrm{u} \text { (OLSy) }\end{array}$ \\
\hline \multirow[t]{2}{*}{$\mathrm{N}$} & - & 1.67 & 1.59 & 2.17 & 2.16 \\
\hline & + & 1.57 & 1.27 & 1.86 & 1.99 \\
\hline \multirow[t]{2}{*}{ Cenv } & - & 1.49 & 1.83 & 2.27 & 2.74 \\
\hline & + & 1.36 & 1.52 & 2.07 & 2.33 \\
\hline
\end{tabular}

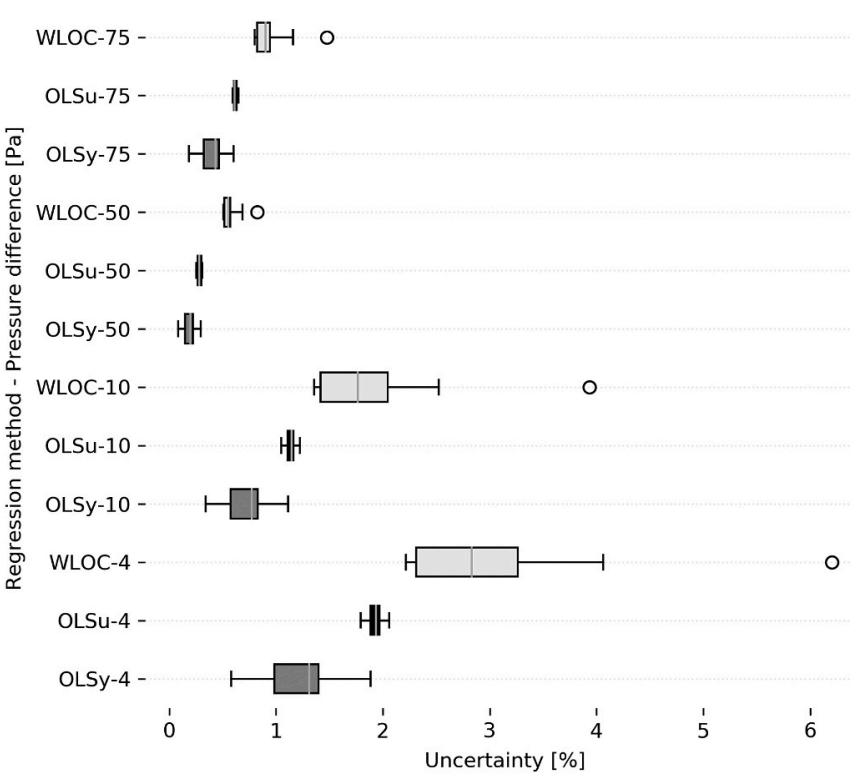

Fig. 9. Uncertainty distribution on airflow rates (q) of the sealing steps at several pressure differences for the considered methods. 


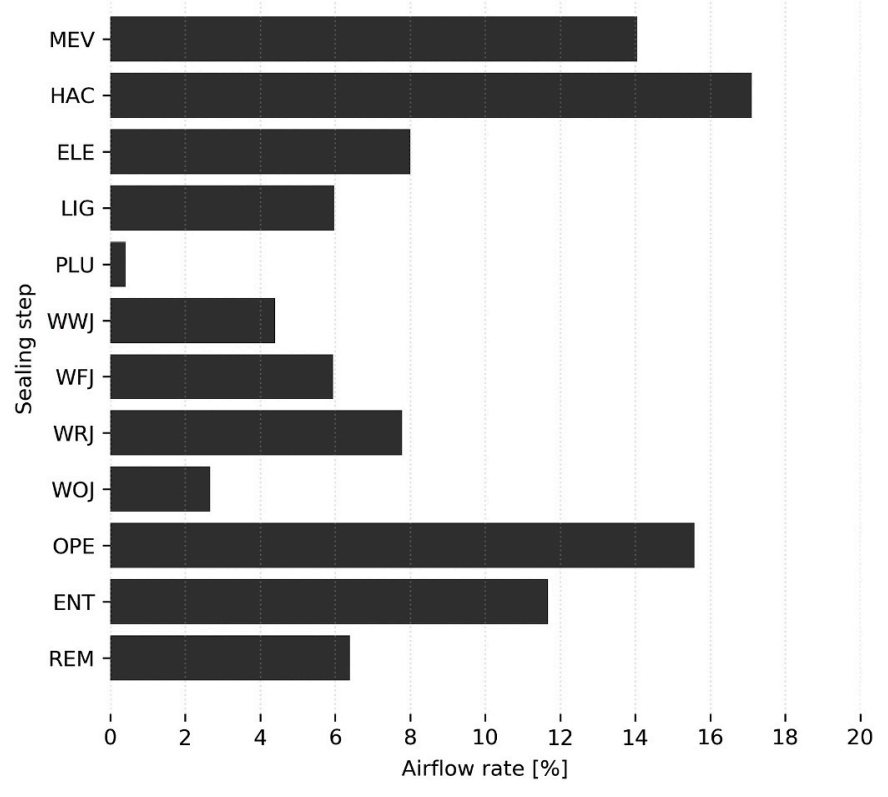

Fig. 10. Average contribution of each type of air leakage path to the overall airtightness performance. Remaining airflow rate referred as REM.

Table 4

Cumulative uncertainty of the ELA, in \%, for the sealing steps of the reductive sealing campaign, at five pressure differences often used to express the variable, with the three considered regression methods.

\begin{tabular}{|c|c|c|c|c|}
\hline Sealing step & $\begin{array}{l}\text { Pressure } \\
\text { difference }\end{array}$ & $\begin{array}{l}\text { OLSy } \\
{[\%]}\end{array}$ & $\begin{array}{l}\text { OLSu } \\
{[\%]}\end{array}$ & $\begin{array}{l}\text { WLOC } \\
{[\%]}\end{array}$ \\
\hline \multirow[t]{5}{*}{ MEV } & 4 & 7.0 & 13.9 & 17.2 \\
\hline & 10 & 4.5 & 8.9 & 11.4 \\
\hline & 50 & 1.3 & 2.5 & 4.7 \\
\hline & 75 & 3.0 & 5.8 & 7.7 \\
\hline & 100 & 4.4 & 8.4 & 10.5 \\
\hline \multirow[t]{5}{*}{ HAC } & 4 & 7.1 & 14.7 & 17.7 \\
\hline & 10 & 4.3 & 9.0 & 11.3 \\
\hline & 50 & 1.2 & 2.3 & 4.3 \\
\hline & 75 & 2.6 & 5.3 & 7.0 \\
\hline & 100 & 3.7 & 7.5 & 9.4 \\
\hline \multirow[t]{5}{*}{ ELE/LIG/PLU } & 4 & 8.3 & 15.8 & 24.1 \\
\hline & 10 & 5.3 & 10.1 & 16.4 \\
\hline & 50 & 1.6 & 2.8 & 5.8 \\
\hline & 75 & 3.7 & 6.7 & 9.9 \\
\hline & 100 & 5.3 & 9.7 & 14.0 \\
\hline WWJ/WFJ/WRJ/ & 4 & 10.3 & 19.4 & 28.3 \\
\hline \multirow[t]{4}{*}{ WOJ } & 10 & 5.6 & 10.4 & 16.4 \\
\hline & 50 & 1.2 & 2.1 & 4.3 \\
\hline & 75 & 2.5 & 4.6 & 6.8 \\
\hline & 100 & 3.4 & 6.2 & 9.1 \\
\hline \multirow[t]{5}{*}{ OPE } & 4 & 11.0 & 20.5 & 30.9 \\
\hline & 10 & 6.5 & 12.0 & 19.1 \\
\hline & 50 & 1.6 & 2.8 & 5.6 \\
\hline & 75 & 3.5 & 6.2 & 9.2 \\
\hline & 100 & 4.8 & 8.7 & 12.4 \\
\hline \multirow[t]{5}{*}{ ENT } & 4 & 13.2 & 24.6 & 37.0 \\
\hline & 10 & 8.0 & 14.8 & 23.8 \\
\hline & 50 & 2.2 & 3.7 & 7.5 \\
\hline & 75 & 4.7 & 8.5 & 12.5 \\
\hline & 100 & 6.7 & 12.0 & 17.2 \\
\hline \multirow[t]{5}{*}{ Average } & 4 & 9.9 & 18.8 & 27.5 \\
\hline & 10 & 6.0 & 11.2 & 17.4 \\
\hline & 50 & 1.6 & 2.8 & 5.6 \\
\hline & 75 & 3.5 & 6.4 & 9.2 \\
\hline & 100 & 4.9 & 9.0 & 12.7 \\
\hline
\end{tabular}

pressure differences remains low despite the regression method used. The maximum uncertainty occurs at $4 \mathrm{~Pa}$ of pressure difference when using the WLOC regression method, averaging $3.0 \%, 1.9 \%$, and $1.2 \%$, for WLOC, OLSu and OLSy, respectively. The minimum values always happen at the centroid of the measured pressures (at $40 \mathrm{~Pa}$ ), as reported in previous studies [33].

\section{Discussion}

\subsection{Contribution of air leakage paths}

The valving effect, identified in the results, gives strength to the use of the average of pressurization and depressurization tests when assessing airtightness performance, particularly in naturally ventilated buildings where both pressure modes can simultaneously occur at different parts of the envelope.

Considering average values of airflow rates and neglecting any kind of uncertainty in measurements, one can quantify the contribution of each type of air leakage path to the overall airtightness of the case study. The air leakage that remained at the end of the reductive sealing campaign is referred solely as REM (Fig. 10).

A significant dispersion of the airflow rate between types of air leakage paths was observed. This is in line with findings in previous studies and the relative contributions are in fair agreement with a reported range of results $[16,35]$. For instance, if one compares ceiling details data, equivalent to the sum of LIG and WRJ, the results of the test pointed to a $14 \%$ contribution to the total air leakage against an average of $18 \%$ found in the literature [35]; mechanical ventilation MEV was $14 \%$ compared with the $13 \%$ of the literature [16]; and heating and air conditioning elements was $17 \%$ against $15 \%$ reported in Ref. [35].

\subsection{Cumulative effect of the reductive sealing technique}

As seen in the results section, the airflow and ELA uncertainty of individual sealing steps have different impacts depending on the used regression methods, but generally small, even at low pressure differences. However, the application of a reductive sealing technique implies that any current result is dependent on earlier results. Therefore, by incrementing the number of sealing steps, one adds additional uncertainty to future results.

To evaluate this cumulative effect, some sealing steps were grouped based on three premises: the type of air leakage paths share such characteristics regarding geometry and overall behaviour that can be assessed as a whole; the sealing steps are consecutive; the interpretation of the results becomes tangible to grasp and provides relevant meaning.

The last point refers to the proportionality of measured ELA and

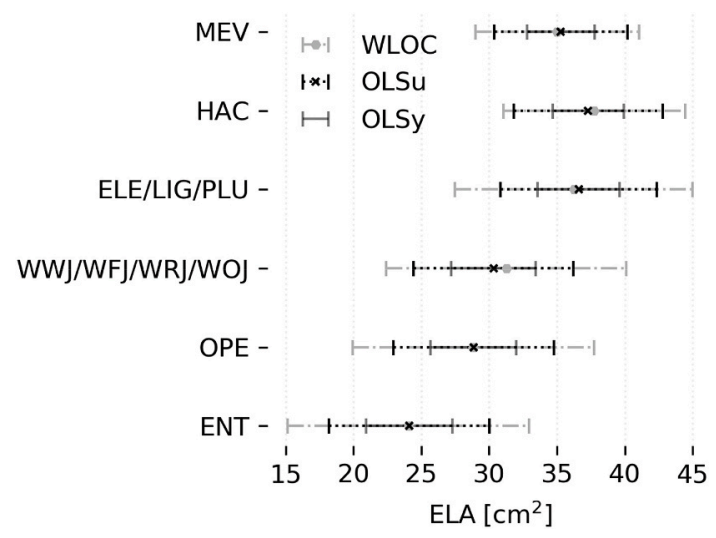

Fig. 11. Cumulative uncertainty of the ELA, in $\mathrm{cm}^{2}$, for the considered groups of sealing steps, at $4 \mathrm{~Pa}$ of pressure difference, with the three considered regression methods. 
Table 5

Normalized ELA and lower and upper bounds (in $\mathrm{cm}^{2}$ ) for each type of air leakage path considering OLSy and WLOC at a reference pressure of 4 Pa.

\begin{tabular}{|c|c|c|c|c|c|c|c|c|c|c|c|}
\hline \multirow[t]{2}{*}{ Group } & \multirow[t]{2}{*}{ Qty. } & \multirow[t]{2}{*}{ Metric } & \multirow[t]{2}{*}{ Contribution [\%] } & \multicolumn{4}{|l|}{ OLSy } & \multicolumn{4}{|l|}{ WLOC } \\
\hline & & & & ELA & Unc. & Lower bound & Upper bound & ELA & Unc. & Lower bound & Upper bound \\
\hline MEV & 4 & item & 14.1 & 35.29 & 2.48 & 8.203 & 9.441 & 35.00 & 6.03 & 7.244 & 10.257 \\
\hline HAC & 4 & item & 17.1 & 37.30 & 2.63 & 8.667 & 9.984 & 37.74 & 6.70 & 7.762 & 11.110 \\
\hline \multirow[t]{3}{*}{ ELE/LIG/PLU } & 19 & item & 8.0 & 36.59 & 3.02 & 0.983 & 1.160 & 36.23 & 8.75 & 0.805 & 1.317 \\
\hline & 17 & & 6.0 & & & 0.819 & 0.967 & & & 0.671 & 1.098 \\
\hline & 7 & & 0.4 & & & 0.139 & 0.164 & & & 0.114 & 0.187 \\
\hline \multirow[t]{4}{*}{ WWJ/WFJ/WRJ/WOJ } & 40.8 & $\operatorname{lm}$ & 4.4 & 30.32 & 3.11 & 0.141 & 0.173 & 31.27 & 8.85 & 0.116 & 0.208 \\
\hline & 38.3 & & 5.9 & & & 0.203 & 0.249 & & & 0.167 & 0.299 \\
\hline & 38.3 & & 7.8 & & & 0.266 & 0.327 & & & 0.219 & 0.392 \\
\hline & 35.1 & & 2.7 & & & 0.100 & 0.122 & & & 0.082 & 0.147 \\
\hline OPE & 25.6 & $\operatorname{lm}$ & 15.6 & 28.85 & 3.17 & 1.003 & 1.251 & 28.82 & 8.90 & 0.778 & 1.473 \\
\hline ENT & 5.9 & $\operatorname{lm}$ & 11.7 & 24.10 & 3.17 & 3.548 & 4.623 & 24.06 & 8.90 & 2.569 & 5.586 \\
\hline
\end{tabular}

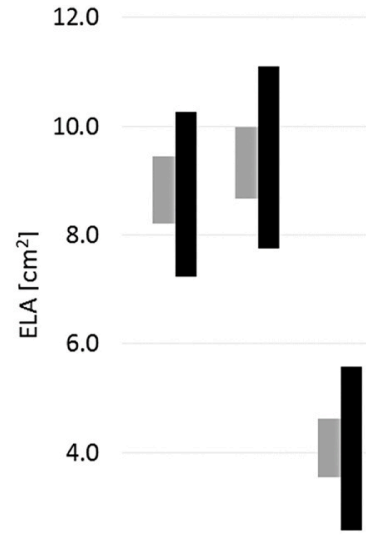

2.0
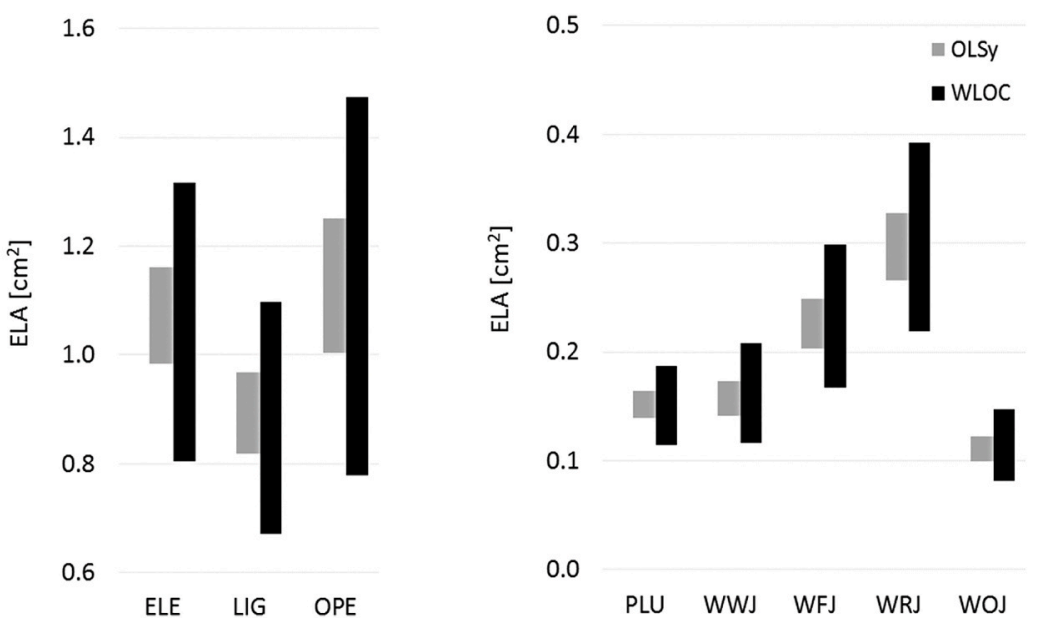

Fig. 12. Normalized ELA ranges for each air leakage path considering OLSy and WLOC at a reference pressure of 4 Pa.

accompanying uncertainty range. In fact, in some sealing steps the calculated ELA is rather small, and as the reductive sealing unfolds, the uncertainty range assumes a value several times higher than ELA itself. This way, ELE/LIG/PLU were grouped, seen as wall penetrations, as well as, WWJ/WFJ/WRJ/WOJ, regarded as joints in assemblies or between assemblies and envelope components (Table 4).

Notice that the smaller the ELA offset between steps, the bigger the relative impact of the uncertainty on the calculated value. This comes to show that while the regression method highly influences the uncertainty range for each sealing step, the planning of the reductive sealing campaign, such as the sealing step order, is the main factor impacting the attained levels of uncertainty. Therefore, the importance of a good definition of the order of the sealing steps is crucial to improve the results reliability. To that end, the qualitative assessment of the air leaks, $i$. e. by smoke tracer, could help on asserting the order of sealing, by identifying the main contributors to the air leakage of the building.

\subsection{Absolute and normalized ELAs}

While for retrofitting decision making, airflow rate measurements together with leakage location assessments may be enough, for design purposes and scenarios simulations, the use of ELA provide more reliable results. Fig. 11 provides data for the considered groups of air leakage paths at a reference pressure of $4 \mathrm{~Pa}$. Most of the existing datasets and libraries provide ELA values at $4 \mathrm{~Pa}$, since it is closer, to the common pressure difference experienced by a building in real conditions.

The literature shows that the WLOC regression method provides a better approximation of the observed values to the calculated ones. With this in mind, and aiming to obtain standard values for types of leakage paths, the ELA at $4 \mathrm{~Pa}$ for the different groups is normalized by its proper metric (Table 5). The ranges obtained with WLOC are on average 2.8 times wider than the ones obtained with OLSy (Fig. 12). Another interesting conclusion is that in absolute values the uncertainty tends to stabilize in the later steps of the campaign. The bigger contributions occur early.

Direct comparison with the previously referred libraries available in the literature is limited as, despite the consideration of the same reference pressure and discharge coefficient, most of the values assume an airflow exponent equal to 0.65 . Still, as an example, the value obtained for the entrance door, ENT, was $24.1 \mathrm{~cm}^{2}$, which is close to the maximum suggested in the ASHRAE library, $27 \mathrm{~cm}^{2}$ [25].

\section{Conclusions}

There is a lack of studies regarding in situ comprehensive assessment of buildings air leakage performance, especially after commissioning. 
The following conclusions were drawn:

- The valving effect was identified, which gives strength to the need of averaging the results of pressurization and depressurization tests.

- Over $93.5 \%$ of the airflow leakage were properly identified. Since the contribution of none of the eleven considered types of air leakage paths exceeded $18 \%$ of the total air change rate, one can conclude that air leakage experiences high dispersion among materials and components of the building envelope;

- The use of smoke tracer is notably advantageous for retrofitting planning and avoiding thorough intervention. Still, there is not a qualitative assessment method without limitations and assessing walls with exterior cladding can be tricky;

- Applying different regression methods returned small differences in average values but substantially different uncertainty values. On average, WLOC calculated uncertainty of airflow rates is 2.6 and 1.7 times higher than the uncertainty calculated with OLSy and OLSu, respectively. Not only the correction of zero-flow measurements is highly impacting the uncertainty of the results, but also the zero-flow approximation component proved to be relevant, as the dispersion of values between measurements in WLOC was substantially superior to OLSy;

- Proper planning regarding the order of sealing steps greatly benefits the quality of the results of a reductive sealing campaign. The strategy should be assessing less impacting air leakage paths first, to control and minimize the uncertainty accumulation effect. The qualitative assessment, i.e. by smoke tracer, could help in the definition of the order of the sealing steps, by identifying the main contributors to the air leakage of the building. Putting similar types of air leakage paths in a consecutive order also improves the reliability of the results, if adjoining of sealing steps is needed for proper data analysis. On average, at a reference pressure difference of $4 \mathrm{~Pa}$, the sealing step uncertainty averaged, $9.9 \%, 18.8 \%$, and $27.5 \%$, for OLSy, OLSu, and WLOC, respectively. At 50 Pa difference, the percentages were of $1.6 \%, 2.8 \%$ and $5.6 \%$;

The modelling of air infiltration provides valuable information for the design and retrofit of buildings. Air infiltration is impacted by both external factors, i.e., terrain, weather, surroundings, and internal characteristics, i.e., boundary conditions on HVAC, air paths characteristics. The discretization of the variables influences the results, even when simulations are partly dynamic. Assessing ELAs uncertainties tackles part of the discretization of air leakage paths. By considering a greater number of error sources, WLOC should be the preferred regression method. In that regard, even though a greater variability on the building performance will result from its application, more reliable will be the simulated air leakage outputs, providing added value either for a risk analysis or establishing ranges of performance. Although the results are specific for the case study, the proposed methodology for air leakage path assessment can be generalized to different buildings.

\section{Declaration of competing interest}

The authors declare that they have no known competing financial interests or personal relationships that could have appeared to influence the work reported in this paper.

\section{Acknowledgments}

This work was financially supported by: Base Funding - UIDB/ 04708/2020 and Programmatic Funding - UIDP/04708/2020 of the CONSTRUCT - Instituto de I\&D em Estruturas e Construções - funded by national funds through the FCT/MCTES (PIDDAC). The author would like to acknowledge the support of FCT - Fundação para a Cienncia e a Tecnologia, the funding of the Doctoral Grant PD/BD/135162/2017, through the Doctoral Programme EcoCoRe.

\section{References}

[1] M. Prignon, G. Van Moeseke, Factors influencing airtightness and airtightness predictive models: a literature review, Energy Build. 146 (2017) 87-97.

[2] R. Urquhart, R. Richman, G. Finch, The effect of an enclosure retrofit on air leakage rates for a multi-unit residential case-study building, Energy Build. 86 (2015) 35-44.

[3] J. Jokisalo, J. Kurnitski, M. Korpi, T. Kalamees, J. Vinha, Building leakage, infiltration, and energy performance analyses for Finnish detached houses, Build. Environ. 44 (2) (2009) 377-387.

[4] T. Kalamees, M. Korpi, L. Eskola, J. Kurnitski, J. Vinha, The distribution of the air leakage places and thermal bridges in Finnish detached houses and apartment buildings, in: BT-8th Symposium on Building Physics, 2008, pp. 1095-1102.

[5] T. Kalamees, Air tightness and air leakages of new lightweight single-family detached houses in Estonia, Build. Environ. 42 (6) (2007) 2369-2377.

[6] AFNOR, FD P50-784:2016 - Guide d'application de la norme NF EN ISO 9972 , 2016.

[7] SPF Economie, STS-P 71-3 Etanchéité à l'air des bâtiments Essai de pressurisation, 2014.

[8] B. Moujalled, V. Leprince, and A. B. Mélois, "French database of building airtightness, statistical analyses of about 215,000 measurements : impacts of buildings characteristics and seasonal variations," Proc. 39th AIVC-7th TightVent5th Vent. Conf 18-19 Sept. (pp. 40-49). (Juan-Les-Pins AIVC).

[9] A.B. Mélois, B. Moujalled, G. Guyot, V. Leprince, Improving building envelope knowledge from analysis of 219,000 certified on-site air leakage measurements in France, Build. Environ. 159 (2019).

[10] M.W. Liddament, "A Guide to Energy Efficient Ventilation," Air Infiltration Vent, in: Center, (AIVC)., 1996, p. 252.

[11] M.H. Sherman, R. Chan, Building Airtightness: Research and Practice, vols. 1-46," Lawrence Berkeley Natl. Lab., no, 2004. February.

[12] R. Stephen, Airtightness in UK Dwellings. Information Paper IP1/00, "Watford, 2000 .

[13] D. Johnston, R.J. Lowe, Improving the airtightness of existing plasterboard-lined load-bearing masonry dwellings, Build. Serv. Eng. Technol. 27 (1) (Feb. 2006) $1-10$.

[14] P.J. Jones, G. Powell, Comparison of air infiltration rate and air leakage tests under reductive sealing for an industrial building, in: 10th AIVC Conference "Progress and Trends in Air Infiltration and Ventilation Research" Espoo, 25-28 September 1989. Finland.

[15] S. Nabinger, A. Persily, Impacts of air tightening retrofits on ventilation rates and energy consumption in a manufactured home, Energy Build. 43 (11) (2011) 3059-3067.

[16] D.J. Dickerhoff, D.T. Grimsrud, R.D. Lipschutz, Component Leakage Testing in Residential Buildings, " Ernest Orlando Lawrence Berkeley National Laboratory, Berkeley, CA (US), 1982.

[17] M. Sherman, L. Palmiter, Uncertainty in Fan Pressurization Measurements, 1995.

[18] International Organization for Standardization (ISO), Evaluation of measurement data - guide to the expression of uncertainty in measurement, Int. Organ. Stand. Geneva 50 (2008) 134. September.

[19] F.R. Carrié, V. Leprince, Uncertainties in building pressurisation tests due to steady wind, Energy Build. 116 (2016) 656-665.

[20] M. Prignon, A. Dawans, S. Altomonte, G. Van Moeseke, A method to quantify uncertainties in airtightness measurements: zero-flow and envelope pressure, Energy Build. 188-189 (2019) 12-24.

[21] C. Delmotte, Airtightness of buildings - considerations regarding the zero-flow pressure and the weighted line of organic correlation, Nottingham, UK, in: In 38th AIVC Conference "Ventilating Healthy Low-Energy Buildings" vols. 13-14, 2017. September 2017.

[22] François Rémi Carrié, P. Wouters, Technical Note AIVC 67 Building Airtightness: a Critical Review of Testing, Reporting and Quality Schemes in 10 Countries, 2012.

[23] M. De Strycker, L. Van Gelder, V. Leprince, Quality framework for airtightness testing in the Flemish Region of Belgium - feedback after three years of experience, in: 39th AIVC Conference. Smart Ventilation for Buildings, 2018.

[24] M. Orme, N. Leksmono, Ventilation Modelling Data Guide 5, no, AIVC Guid, 2002, p. 80, 2002.

[25] 2001 ASHRAE, ASHRAE Handbook : Fundamentals, ASHRAE, Atlanta, GA, 2001.

[26] A. Persily, Repeatability and accuracy of pressurization testing, in: Proc. ASHRAE/ DOE Conf. "Thermal Perform. Exter. Envel. Build. II,", 1982, pp. 380-390.

[27] W.E. Murphy, D.G. Colliver, L.R. Piercy, Repeatability and reproducibility of fan pressurization devices in measuring building air leakage, Ashrae Trans vol. 97 (2) (1991) 885-895.

[28] M. Prignon, A. Dawans, and G. Van Moeseke, "Uncertainties in airtightness measurements: regression methods and pressure sequences," Proc. 39th AIVC-7th TightVent-5th Vent. Conf. vols. 18-19 Sept. (pp. 40-49). Juan-Les-Pins AIVC., Sep. .

[29] C. Delmotte, J. Laverge, Interlaboratory test for the determination of repeatability and reproducibility of buildings airtightness measurements, in: 32nd AIVC Conf. ; 1st TightVent Conf. Towar. Optim. Airtightness Perform., No, 2011. October 2011.

[30] C. Delmotte, Airtightness of buildings - calculation of combined standard uncertainty, Athens, Greece, in: 34th AIVC Conference " Energy Conservation Technologies for Mitigation and Adaptation in the Built Environment: the Role of Ventilation Strategies and Smart Materials”,, 2013, 25-26 September 2013.

[31] M. Prignon, A. Dawans, and G. Van Moeseke, "Quantification of uncertainty in zero-flow pressure approximation," Conf. 40th AIVC - 8th TightVent 6th Vent. Conf. From Energy Cris. To Sustain. Indoor Clim. 40 Years AIVC, Ghent, Belgium, Oct. . 
[32] H. Okuyama, Y. Onishi, Reconsideration of parameter estimation and reliability evaluation methods for building airtightness measurement using fan pressurization, Build. Environ. 47 (2012) 373-384.

[33] M. Prignon, C. Delmotte, A. Dawans, S. Altomonte, G. van Moeseke, On the impac of regression technique to airtightness measurements uncertainties, Energy Build. 215 (2020) 109919.

[34] R.D. Lipschultz, Infiltration and Indoor Air Quality in Energy Efficient Houses in Eugene, Oregon LBL-12924, " Berkeley, California, 1981.

[35] R.S.C. Reinhold, Component leakage areas in residential buildings, in: 4th AIVC Conference, Elm, Switzerland, 1983.

[36] V. Cardoso, N. Ramos, R. Almeida, P. Pereira, M. Almeida, R. Sousa, In-situ and laboratory airtightness tests of structural insulated panels (SIPs) assemblies, in: 39th AIVC Conference - Smart Ventilation For Buildings, 2018, pp. 75-82.

[37] CEN, EN 12207 Windows and Doors. Air Permeability. Classification, 2016.
[38] 2015 ISO, BS EN ISO 9972, Thermal Performance of Buildings. Determination of Air Permeability of Buildings. Fan Pressurization Method, 2015.

[39] ASTM, ASTM E1186 - 17 Standard Practices for Air Leakage Site Detection in Building Envelopes and Air Barrier Systems, 2017.

[40] Retrotec Inc, Gauge Specifications For DM-2, 2010.

[41] Retrotec Inc, Spec-Blower Door vol. 1000, 2012.

[42] M.H. Sherman, Infiltration-pressurization Correlation: Simplified Physical Modeling, Lawrence Berkeley Natl. Lab., 1980.

[43] M. Modera, P. Levin, M. Sherman, A detailed examination of the LBL infiltration model using the mobile infiltration test unit, in: ASHRAE Trans. vol. 89, Jan. 1983.

[44] E. Barreira, R.M.S.F. Almeida, M. Moreira, An infrared thermography passive approach to assess the effect of leakage points in buildings, Energy Build. 140 (2017) 224-235. 